\title{
O Estreito de Magalhães redescoberto: CIÊNCIA, POLÍTICA E COMÉRCIO NAS EXPEDIÇÕES DE EXPLORAÇÃO NAS DÉCADAS DE 1820 E 1830
}

\author{
Strait of Magellan rediscovered: science, politics, commerce \\ and the exploring expeditions during the 1820's and 1830's
}

\section{Gabriel Passetti ${ }^{1}$}

RESUMO

Este artigo discute o crescente interesse das potências ocidentais no Estreito de Magalhães, Patagônia e Terra do Fogo nas primeiras décadas do século XIX. São conectados os objetivos estratégicos dos governos aos comerciais de companhias de caça e comércio para a compreensão do financiamento de expedições oficiais de exploração e mapeamento da região. São analisados os relatos de dois comandantes britânicos a serviço da Marinha Real que percorreram aquela região e procuraram conciliar ciência e interesses pessoais na publicação de relatos de suas viagens, descrevendo descobertas, aventuras, a desconstrução de lendas e os tensos e conflituosos contatos com os indígenas locais.

Palavras-chave: Estreito de Magalhães. Relatos de viagens. Expedições científicas de mapeamento. Marinha Real ânica. Phillip Parker King.

\section{ABSTRACT}

This article focuses on the growing interests of Western great powers on the Strait of Magellan, Patagonia and Tierra de Fuego during the first half of the $19^{\text {th }}$ century. Strategic government objectives are connected to those of commercial and hunting companies to comprehend the funding of official exploring and mapping expedition to these lands. It analyses two travel accounts of British commanders of the Royal Navy who travelled and described that region. They intended to conciliate science and personal interests when publishing their travel books describing discoveries, adventures and the 
deconstruction of tales and the conflictuous contacts with local native peoples.

Keyword: Strait of Magellan. Travel accounts. Exploring expeditions. British Royal Navy. Phillip Parker King.

\section{Introdução}

Abril de 1829: duas expedições distintas, enviadas pela Marinha Real Britânica - uma com o His Majesty's Ship (HMS) Chanticleer e a outra com os HMS Adventure e Beagle realizavam serviços de exploração e mapeamento no Estreito de Magalhães. Ao mesmo tempo, mais de uma dezena de embarcações não militares, sob diversas bandeiras, atravessavam a região antes da chegada do inverno. $O$ tráfego naquela inóspita região era grande, o interesse da Grã-Bretanha e das outras potências ocidentais também.

Este artigo discute, a partir da leitura crítica de relatos de dois comandantesexploradores britânicos do período, os motivos que levaram as principais potências ocidentais a se preocupar e investir na região, conciliando interesses científicos, estratégicos e comerciais e as relações estabelecidas com os povos indígenas locais. Procurase compreender como os autores destes diários entendiam, viam e descreviam o que e quem encontravam.

\section{Um estreito entre o Atlântico e o Pacífico: rota de passagem para os europeus}

Vinte e um anos após a chegada de Cristóvão Colombo à América, o explorador Vasco Nuñez de Balboa avistou o mar após cruzar o istmo do Panamá, batizando o local de "Mar do Sul", ainda sem saber que era esta a tão desejada via de conexão com a Índia e a China. A partir de então, a Coroa Espanhola passou a investir em localizar a conexão marítima a este novo corpo d'água (GUEDES, 2007: p. 10)

Alcançado pela primeira vez pelos europeus em novembro de 1520, o "Mar do Sul" foi então rebatizado pelo navegador português Fernão de Magalhães como "Oceano Pacífico". Suas águas pacíficas simbolizavam uma marcante oposição à natureza hostil da zona de confluência de correntes marítimas e de vento posteriormente nomeada por "Estreito de Magalhães": 
Descobrimos, no dia 21 de outubro [de 1520], aos $52^{\circ}$ de latitude meridional, um estreito (...). Como pudemos constatar em seguida, tem quatrocentas e quarenta milhas de comprimento (...) e desemboca em outro mar, a que chamamos de Pacífico. O estreito é rodeado de montanhas muito altas e cobertas de neve. É tão profundo que, mesmo estando bastante próximo da terra, não se encontrava fundo para a âncora, nas vinte e cinco ou trinta braças (PIGAFETTA, 2005: pp. 65-66).

A breve descrição da primeira travessia por europeus do estreito - que logo viria a ser batizado com o nome do comandante da expedição - foi escrita por Antonio Pigafetta, um dos poucos sobreviventes da inédita viagem de circum-navegação do planeta. Seu relato publicado foi lido, relido e comentado por praticamente todos os viajantes que se destinaram ao extremo sul da América e ao Oceano Pacífico nos séculos seguintes. Seu texto inaugurou as descrições e inseriu na cultura ocidental uma série de imagens e ideias a respeito do Estreito de Magalhães, da Patagônia e da Terra do Fogo. Sua natureza hostil e seus povos ditos gigantescos aguçaram a curiosidade e estas histórias foram repetidas e transformadas através dos viajantes e seus escritos, chegando ainda recorrentes ao início do século XIX.

O fluxo de gente e navios europeus por aquela conexão marítima entre o Atlântico e o Pacífico foi restrito até as décadas finais do século XVIII. Os colonizadores espanhóis preferiram atravessar o continente por terra a enfrentar o Estreito, suas correntezas, clima e ventanias. As incursões por terra, pela Patagônia e Terra do Fogo, foram restritas e mantiveram a região envolta em uma série de lendas.

Evitado pelos colonizadores espanhóis, o Estreito de Magalhães passou a ser gradativamente mais visitado à medida que cresceram os fluxos comerciais e populacionais entre a Europa e o Extremo Oriente, em especial à China e à Índia, para onde eram vendidos produtos exóticos e de onde se importavam cada vez mais produtos de luxo, como seda, porcelanas e marfim (WASHBROOK, 1999).

A Revolução Industrial colocou o Estreito no mapa das prioridades das potências ocidentais, pois incentivou a busca por novos mercados - e a ampliação de antigos incentivando os ingleses a aumentar sua presença na Índia (LANDES, 2005). As inovações nas tecnologias náuticas também possibilitaram viagens mais longas, seguras e produtivas, proporcionando forças e recursos para que viagens de exploração e mapeamento contassem com novos parâmetros e referenciais pautados no Iluminismo e no racionalismo (CALDER, 1999).

A conjunção destes três fatores - mercados, tecnologias e recursos financeiros - levou os governos das principais potências ocidentais a enviar para a América do Sul, e para o Estreito de Magalhães em especial, expedições oficiais com o objetivo de elaborar novas e precisas cartas náuticas da região (CICERCHIA; O'MEAGHER, 2003). Britânicos (BRIDGES, 
2007), franceses (GUILLON, 1986), espanhóis (MARTIN, 2010), russos (BRAUND, 2003) e estadunidenses (JUNQUEIRA, 2012) percorreram as costas e interiores do continente, descreveram seus recursos naturais, fauna e flora, populações e regimes de governo, contestaram antigas lendas e colaboraram na construção de imagens sobre a região (GERBI, 1996).

Estas expedições respondiam a diferentes pressões. O crescente tráfego marítimo pela região sofria com as parcas informações sobre correntes marítimas e de ventos, baixios, bancos de areia, rochas e todos os obstáculos enfrentados pelos navios e que levavam a recorrentes naufrágios e aos consequentes prejuízos materiais e humanos.

Além do interesse econômico imediato, os governos das potências ocidentais também procuravam aproveitar a momentânea instabilidade política decorrente das independências da Argentina e do Chile e a indefinição de fronteiras no extremo sul do continente para tentar instalar na região postos de vigilância e controle deste importante ponto de passagem e conexão marítima.

Havia também a corrida para a afirmação de lugares e saberes no campo científico e para a aquisição de itens para as coleções de história natural das metrópoles (SALVATORE, 2007). Para os comandantes-exploradores, não bastava apenas elaborar as cartas náuticas: eles também mediam e nomeavam as montanhas, subiam rios, coletavam espécimes da flora e da fauna, geológicos, históricos e etnológicos. Era preciso, no entendimento daqueles homens, acumular conhecimento e demonstrar a superioridade de seu reino (HENARE, 2005). Às potências ocidentais, interesses geopolíticos, econômicos e o prestígio científico pressionavam pelo envio de expedições oficiais de mapeamento do Estreito de Magalhães e das costas sul-americanas.

Dezenas de expedições foram enviadas pela Grã-Bretanha para o mapeamento do planeta. O modelo para elas era a atuação do lendário comandante James Cook quem, na segunda metade do século XVIII, estabeleceu os novos parâmetros para a elaboração de mapas e cartas náuticas com precisão, aparelhos e metodologia científica. Este militar também foi o responsável, em suas viagens, por inserir nas malhas formais do Império Britânico uma série de ilhas, entre elas a mais destacada a da Austrália.

Em maio de 1826, partiu de Plymouth uma destas expedições, com duas embarcações os HMS Adventure e Beagle. Após mapearem a ilha da Madeira, Tenerife, Cabo Verde e Trindade, os navios seguiram até o Rio de Janeiro e de lá diretamente para o Estreito de Magalhães, foco central da expedição.

O comandante desta expedição era Phillip Parker King, um homem do império (LAMBERT; LESTER, 2006). Filho do governador da colônia de Sydney, ele foi educado na metrópole e ingressou na Marinha Real, em 1807. Após quatro viagens de mapeamento nas 
costas das colônias australianas, entre 1817 e 1823, reunia experiência e coragem para comandar o mapeamento do Estreito de Magalhães (HORDERN, 2003). Lá, somou esforços com a expedição do capitão Henry Foster, do HMS Chanticleer. Havia, desta forma, três navios de mapeamento britânicos percorrendo o arquipélago no entorno do Estreito de Magalhães, no ano de 1829, o que explicita o interesse naquela região. Após o retorno destas expedições, outras continuaram percorrendo o local - como a do HMS Beagle, entre 1832 e 1833, sob o comando de Robert FitzRoy.

Este último compilou e publicou os relatos de suas viagens e as de King, em 1839, sob o titulo Narrative of the surveying voyages of His Majesty's Ships Adventure and Beagle between the years 1826 and 1836, describing their examination of the southern shores of South America, and the Beagle's circumnavigation of the globe (FITZROY, 1839; KING, 1839).

A leitura e análise dos escritos destes comandantes da Marinha Real Britânica sobre o Estreito de Magalhães é uma chave para a compreensão dos múltiplos interesses envolvidos na seleção dos locais a serem mapeados, o financiamento das viagens, os interesses pessoais, governamentais e de companhias envolvidos em tais empreendimentos. Os relatos de viagens são fontes singulares, distintas e díspares entre si, ricas para a compreensão das formas pelas quais aqueles homens a serviço oficial da Coroa viam, entendiam e se relacionavam com populações e ambientes visitados (BORM, 2004).

Representantes de seus governos, os comandantes navais das primeiras décadas do século XIX muitas vezes publicaram os relatos de suas viagens. Eles liam os viajantes anteriores e sabiam que, além de nomear baías e montanhas, para colocar seus nomes no rol dos grandes navegadores, deveriam materializar suas expedições e construir narrativas de seus feitos. No entendimento da crítica literária Mary-Louise Pratt, "eis aqui a linguagem encarregada por si só de fazer o mundo, e com altos interesses em jogo. Como os exploradores vieram a notar, rios de dinheiro e prestígio dependiam do crédito que conseguissem fazer com que outros lhes atribuíssem" (PRATT, 1999: p. 343).

Transformar os diários de bordo, relatórios e anotações pessoais em um livro a ser publicado era trabalho árduo e significava um enorme esforço aos comandantes que a isto se dispusessem. Havia muitos interesses por trás destas publicações, tanto os pessoais quanto outros, mais amplos - eles procuravam defender ou criticar saberes estabelecidos, defender pontos interesses vinculados a grupos específicos e participar de debates teóricos: "se o viajante não era apenas uma fonte de informação, mas também de análises, (...) deve-se considerar também como os viajantes partiram da Europa conhecendo os debates com os quais eles pretendiam contribuir" (RUBIÉS, 2007: p. 257). 
A leitura dos relatos dos comandantes da Marinha Real Britânica permite a identificação de uma série de objetivos estratégicos britânicos no envio daquelas expedições.

Mapear e precisar as coordenadas geográficas das principais ilhas atlânticas na rota entre a Europa e a América do Sul foi a primeira atividade da expedição comandada por Phillip Parker King e esta não deve ser entendida como corriqueira. Inscrever nas cartas náuticas a localização precisa, as rotas seguras e os riscos na aproximação a estes portos era vital aos interesses britânicos e se conectava ao movimento de conquista e estabelecimento de bases navais por todo o planeta durante as Guerras Napoleônicas - no Cabo da Boa Esperança, em Penang (Malásia), em Malta e nas Ilhas Jônicas, por exemplo (DARWIN, 2009). Naquelas primeiras décadas do século XIX, os britânicos construíam uma intensa rede de apoio às suas marinhas de guerra e mercante e era preciso que os comandantes tivessem certeza dos caminhos a serem seguidos - por isso os mapas deveriam ser precisos.

Ao chegar ao Estreito de Magalhães, Phillip Parker King procurou pontos interessantes para o estabelecimento de uma base para a Marinha Real no local. Caso se concretizasse esta conquista, seria uma estrondosa vitória para a manutenção e garantia dos interesses britânicos nesta importante via de passagem do comércio internacional. Segundo o comandante:

\footnotetext{
Em praticamente todo relato publicado sobre o Estreito de Magalhães há notas sobre Port Famine, o que me levou a considerá-lo um possível local adequado para nossos objetivos. Após investigações no local, deduzi que este oferecia tantas vantagens que não hesitei em transformá-lo em nosso quartel-general (KING, 1839: p. 26)
}

Port Famine foi o nome dado a uma baía protegida e com farta vegetação pelo lendário corsário britânico Thomas Cavendish que, em sua trágica tentativa de travessia do Estreito no século XVI aportou por lá. O local já era conhecido, pois havia também servido de base e recebido uma tentativa infrutífera de instalação de fortes anos antes, quando os espanhóis fundaram San Filipe - em homenagem ao monarca Filipe II - em tentativa de frear as investidas de Francis Bacon.

As tentativas de ocupação efetiva da área não foram bem-sucedidas, por conta do clima hostil, da dificuldade para a agricultura, da dependência do fornecimento de víveres de pontos longínquos e das consequentes e recorrentes crises de fome que acabaram dando o nome popular ao lugar. Se estas haviam sido as dificuldades enfrentadas pelos colonizadores espanhóis no século XVI e por seus adversários corsários ingleses, a situação pouco mudou no início do XIX. King montou barracas, tentou organizar agricultura, pescar, caçar. Os marinheiros se revoltaram duas vezes e, para evitar colocar em risco toda a 
expedição, eles também abandonaram Port Famine - ou Puerto del Hambre, como o chamavam os espanhóis.

A Marinha Britânica não desistiu, no entanto, de estabelecer bases no extremo sul do Atlântico e enviou, em 1832, dois navios, os HMS Clio e Tyne, para tomar posse das ilhas Malvinas. Na sequência, o comandante Robert FitzRoy aportou por lá com o HMS Beagle para precisar a localização do arquipélago, mapeá-lo e inseri-lo formalmente nos mapas do Império Britânico. A conquista das ilhas não foi, segundo o referido comandante, conflituosa - apesar dos interesses de diferentes Estados em disputa:

Enquanto os Estados Unidos da América e Buenos Aires estavam discutindo, a Grã-Bretanha, seguindo os solenes avisos enviados a Buenos Aires (em especial os protestos do Sr. Parish ao governador, em novembro de 1829), ordenou ao comandante-em-chefe da estação da América do Sul que enviasse um navio de guerra para voltar a hastear a bandeira britânica nas ilhas Falkland para assegurar seus direitos de soberania e para embarcar todos os pertences do governo de Buenos Aires de volta (FITZROY, 1839: p. 239).

Esta descrição do comandante FitzRoy demonstra a compreensão britânica de sua posição no sistema internacional e de sua força. Não havia espaço para negociações sobre seus interesses com um Estado em formação e crise (Buenos Aires), nem tampouco com a antiga colônia com pretensões expansionistas (Estados Unidos) (BELL, 2007). Representante da Coroa e escrevendo para britânicos, o comandante foi claro e preciso na defesa dos interesses do Império. Não havia discussão diplomática, mas ele se esforçou para justificar aos leitores a posição adotada:

A descoberta, ocupação prévia e colonização de territórios novos e inabitados dá o direito à posse? Se sim, a Grã-Bretanha é proprietária oficial dessas ilhas. Davis primeiro as descobriu; Hawkins as nomeou; Strong foi o primeiro a desembarcar nelas; e (com exceção aos franceses), Byron primeiro tomou posse oficial delas; e (novamente com exceção aos franceses), Macbride primeiro as colonizou (...). Os espanhóis não as descobriram, nem desembarcaram, nem colonizaram as Falklands antes dos ingleses; e seu único direito está em um fundamento instável de uma bula papal, segundo a qual a Espanha poderia reivindicar o Taiti, as Ilhas Sandwich ou a Nova Zelândia (FITZROY, 1839: pp. 236-237).

Ao público leitor de Narrative, FitzRoy defendeu a soberania britânica sobre as ilhas agora denominadas Falkland - amparado pela listagem de fatos históricos que justificavam, 
pelas diferentes análises jurídicas, o direito da Grã-Bretanha sobre o arquipélago. Para ele, em tom irônico e crítico, apenas o desprestigiado Tratado de Tordesilhas garantiria direitos espanhóis supostamente herdados pelos portenhos sobre aquelas ilhas. E ele não discutiria a irrelevância do antigo acordo entre Portugal, Espanha e o papado.

No entanto, não eram apenas interesses estratégicos que faziam o governo britânico defender sua soberania sobre o longínquo arquipélago das Falkland/Malvinas. Segundo as instruções do Almirantado, de novembro de 1831, havia também interesses econômicos:

\begin{abstract}
Antes de sair da costa leste da América do Sul, é necessário lembrar de nossa presente ignorância sobre as ilhas Falkland, apesar de estas serem constantemente visitadas. $O$ tempo que será empregado para um mapeamento preciso deste grupo de ilhas é desproporcional ao seu valor. No entanto, elas são o porto seguro para baleeiros e (...) o conhecimento preciso do local para onde se dirigem demanda o sacrifício de tempo no levantamento dos portos, baías e enseadas mais vantajosos para aportar e desembarcar (FITZROY, 1839: p. 30).
\end{abstract}

Para a compreensão dos motivos que levaram ao envio das expedições de mapeamento ao Atlântico Sul e ao Pacífico, é preciso analisar o papel desempenhado por uma série da navios que não apenas atravessavam o Estreito de Magalhães, mas que tinham naquele local e nos arquipélagos vizinhos sua área de atuação - e estas eram as embarcações das companhias de caça.

\title{
O Estreito de Magalhães como destino final de viajantes
}

No início do século XIX, havia crescentes mercados para óleos e a fonte principal para sua obtenção era a gordura animal. Utilizados na iluminação pública das cidades que cresciam vertiginosamente na Grã-Bretanha da Revolução Industrial - e em tantas outras do planeta - eles também eram utilizados para a lubrificação das máquinas, além dos usos tradicionais na construção civil e na alimentação.

Os britânicos, com seus colonos na América do Norte, dominavam estes mercados há séculos, tendo como bases as regiões canadenses de Labrador e Newfoundland e a posteriormente independente colônia de Massachusetts, em especial a ilha de Nantucket. Nestes locais, desenvolveu-se uma indústria da caça a focas e baleias com intensa atuação no Atlântico Norte (PHILBRICK, 2001). 
Os colonos quakers de Nantucket se destacaram entre os baleeiros. Suas companhias enriqueceram ao expandir sua zona de atuação e acompanhar os mais recentes inventos tecnológicos do ramo, conciliando o ímpeto caçador, a gana capitalista e a vigilância religiosa característica desta seita protestante (PHILBRICK, 2001: p. 31).

No final do século XVIII, os navios baleeiros estavam mais velozes, possuíam armas mais potentes e passaram a incluir um avanço tecnológico que lhes permitiu uma grande autonomia e a expansão de sua zona de atuação a praticamente todo o planeta: as fornalhas. Construídas com tijolos, estas permitiram que a gordura animal fosse transformada em óleo ainda em alto-mar e que os navios permanecessem navegando até estarem cheios de óleo - e não mais de gordura - portanto ampliaram imensamente sua capacidade de caça, levandoos ao Atlântico Sul, ao Pacífico e à Oceania.

O reflexo da crescente demanda por óleo de origem animal foi o crescimento exponencial da caça aos mamíferos marinhos - baleias, focas, morsas, lobos e leões marinhos - , o rápido enriquecimento das regiões caçadoras - como as costas do Canadá e a ilha de Nantucket, nos EUA - e o esgotamento cada vez mais rápido da caça.

Somente o porto baleeiro de Nantucket abrigava, no começo da década de 1820, uma frota de mais de setenta navios com capacidade de armazenamento, cada um, de praticamente duzentas e cinquenta toneladas de óleo. Na mesma época, os caçadores de foca canadenses já reuniam mais de duzentos e cinquenta veleiros (PHILBRICK, 2001: p. 22).

Estes dados explicitam os motivos econômicos que levaram os governos britânico e estadunidense a investir na tentativa de conquista das ilhas Falkland. Para os caçadores marítimos, o Atlântico Norte não fornecia mais caça suficiente, sendo necessário partir para viagens maiores e para locais cada vez menos conhecidos, pois "os pescadores de baleias (...) não eram apenas caçadores do mar e operários da indústria, mas também exploradores, que avançavam cada vez mais longe em uma região inóspita e mal provida de mapas" (PHILBRICK, 2001: pp. 11-12).

A estas companhias de caça, os arquipélagos do Atlântico Sul e da Oceania eram território livre para a exploração e o Estreito de Magalhães área de trânsito e de atuação. Apesar de encontrarem fartos campos de caça, estas áreas ofereciam enormes riscos, pois eram muito pouco desconhecidas. Os navios dependiam da experiência dos pilotos e sofriam com a falta de informações sobre portos seguros, locais para reabastecimento, rotas, caminhos e perigos. Os naufrágios eram recorrentes e os prejuízos também. As pressões sobre seus governos - fosse o estadunidense, o britânico, ou outros, como o russo ou o francês - foram grandes e se refletiram nos investimentos para a elaboração de cartas náuticas e a conquista de territórios nestas regiões. 
As relações entre as companhias de caça e os navios expedicionários não se restringiram ao campo das pressões políticas e interesses econômicos. A convivência era cotidiana no Estreito e a descrição dos encontros entre estas embarcações, nos relatos publicados dos comandantes Phillip Parker King e Robert FitzRoy demonstram as íntimas relações entre os caçadores e os comandantes-exploradores.

A tradição náutica afirma que, exceto em momentos de guerra, as tripulações dos navios se ajudam em caso de emergências - naufrágios, encalhes, doenças e desabastecimento. É interessante notar como as expedições da Marinha Real Britânica, pensadas para mapear regiões estratégicas e vitais para o comércio e a caça, foram auxiliadas e mantiveram contatos intensos com os veleiros comerciais.

Logo na primeira incursão do comandante King pelo Estreito de Magalhães, sua embarcação, o HMS Adventure cruzou com um veleiro proveniente dos EUA. Seus escritos demonstram o quanto aquela expedição também animava aos estadunidenses e os tranquilos intercâmbios entre os homens das embarcações da antiga metrópole e da antiga colônia com desafios em comum:

Logo no início da manhã, um veleiro caçador de focas dos EUA, retornando do arquipélago Madre de Dios, rumo às ilhas Falkland, ancorou próximo a nós. O sr. Cutler, seu capitão, veio à bordo do Adventure e passou o dia e a noite conosco, repassando muitas informações úteis a respeito da navegação naquele local e as melhores ancoragens no Estreito. Ele me informou sobre um inglês à bordo de sua embarcação, piloto experiente na região, interessado em se transferir ao nosso navio. Eu gentilmente aceitei a oferta de seus serviços (KING, 1839: p. 16).

Ao descrever o intercâmbio com os caçadores de foca estadunidenses nestes termos, o comandante King expressou aos seus leitores britânicos um clima de amizade e fraternidade entre os navegadores que atravessavam a região, sem se preocupar em eventualmente repudiar a concorrência que aqueles poderiam fazer aos súditos britânicos de origem canadense. A King parecia mais interessante demonstrar a relevância internacional dos serviços prestados pela Marinha Real Britânica no Estreito e a aquisição de experiente navegador colaborador na elaboração dos complexos mapas.

O comandante Pringle Stokes, responsável pelo veleiro auxiliar HMS Beagle durante aquela expedição, ao mapear canais e ilhas afastado da embarcação principal, manteve também intensos contatos com veleiros caçadores de foca. Ele encontrou e salvou a tripulação de um veleiro caçador de focas naufragado. Seu atraso em retornar levou o próprio comandante King a temer pela integridade do navio, visto que eram repetidos os casos de naufrágios na região: 
O prazo para o retorno do Beagle expirou no dia $1^{\circ}$ de abril e nossa ansiedade (...) foi crescendo (...). O sr. Sholl informou que o Beagle encontrou um bote pertencente à escuna Prince of Saxe Cobourg, naufragada na enseada Furiosa, na entrada sul do canal Barbara, e que eles rumaram ao porto Galante, para onde o capitão Stokes levou seus botes para auxiliar no resgate aos caçadores de focas. (...) O capitão Stokes logo me informou que conseguiu salvar a tripulação do Prince of Saxe Cobourg. Ele contou com um clima favorável e, apesar de seu guia ter errado a rota algumas vezes, conseguiu alcançar a enseada Furiosa em apenas dois dias. Eles embarcaram o capitão e toda a tripulação do veleiro naufragado, com suas propriedades pessoais e a maior parte das peles de foca que eles já haviam curado (KING, 1839: pp. 65-66).

Esta descrição do comandante King possibilita a compreensão de como, em seu relato, ele construiu uma série de noções sobre a região e a importância de sua expedição. Ele descreveu as dificuldades do clima e da falta de conhecimentos sobre a região que quase impossibilitaram o salvamento à tripulação na navio e expressou suas próprias preocupações quanto a um eventual trágico destino do Beagle. Também é possível a compreensão de quão próximas eram as relações entre os veleiros exploradores e os veleiros caçadores, pois o comandante do navio britânico salvou não apenas a tripulação do navio naufragado, mas também seus objetos pessoais e - mais importante - a valiosa carga de peles de focas.

O próprio comandante King explicou, na sequência, o quão importante era a navegação promovida pelos caçadores de focas e como tais homens eram conhecidos e reconhecidos política e economicamente:

O Prince of Saxe Cobourg, pertencente ao sr. Weddell (cuja viagem ao extremo sul do mundo é tão conhecida), era comandado pelo sr. Matthew Brisbane, colega de Weddell na referida expedição, e havia partido da Inglaterra no verão de 1826 na atual viagem de caça às focas (KING, 1839: p. 66).

Aos leitores de King, acostumados com os relatos das viagens aos confins do planeta, o nome de James Weddell dispensava apresentações e embasava a importância da missão de mapeamento em curso e potencializava o valor do salvamento executado. Ele era bastante conhecido e reconhecido, pois havia publicado, em 1825, os relatos de suas viagens de caça aos arquipélagos do extremo sul do Atlântico, quando se tornou, ao que se saiba, o primeiro homem a localizar diversas ilhas (WEDDELL, 2011). 
Exímio navegador, tornou-se reconhecido internacionalmente e seu nome passou a simbolizar os comandantes-caçadores do período, conciliando coragem e ousadia à nova tecnologia marítima britânica, aos interesses comerciais e à busca por fama. Seu nome batiza o Mar de Weddell, na Antártida, a Ilha Weddell, no arquipélago Falklands/Malvinas e, ironicamente, a Foca-de-weddell (Leptonychotes weddellii), espécie característica da região e uma das mais caçadas por seus navios.

Suas idas às ilhas Shetland do Sul e Falkland/Malvinas abriram novos campos à caça de focas e aos baleeiros e a publicação de seu relato de viagens o colocou no rol dos grandes navegadores e publicizou seu nome, o de sua companhia e seus feitos. Estes incentivaram as empresas que atuavam nestes ramos a pressionar o governo pela anexação formal de tais lucrativos territórios à jurisdição do Império.

Weddel fez parte de um grupo de homens que, após encerradas as Guerras Napoleônicas, saiu da Marinha Real Britânica, no programa de diminuição de comandantes, marinheiros e oficiais navais. Enquanto muitos continuaram na carreira militar, acompanhando o crescimento vertiginoso da influência e do poder britânicos nas primeiras décadas do século, ele e outros procuraram conciliar a experiência naval com os interesses particulares e abriram companhias de marinha mercante e/ou de caça.

Ao descrever a operação realizada pela tripulação do Beagle para salvar os homens e a carga do Prince of Saxe Cobourg, King não expressou aos seus leitores apenas a camaradagem dos homens do mar, nem tampouco apenas as aproximações entre os comandantes. Ao citar e comentar várias vezes o nome da embarcação, explicitou ao seu leitor as conexões muito próximas entre as companhias e a alta nobreza europeia: o príncipe de Saxe-Coburgo da época era Leopoldo, general do exército russo de origem alemã, casado em 1816 com a princesa Charlotte de Gales, segunda na linha sucessória britânica que veio a falecer no ano seguinte durante o parto de seu filho natimorto. Leopoldo se tornou, em 1831, o rei da Bélgica.

James Weddell, seu capitão Brisbane e os comandantes Phillip Parker King, Pringle Stokes e Robert FitzRoy eram todos navegadores britânicos e estavam unidos pela irmandade do mar. Conterrâneos e antigos companheiros de guerra, apoiavam-se mutuamente e se tornaram uma força política e econômica de bastante influência no Reino Unido do começo do século XIX, conseguindo fazer o Almirantado aprovar importantes e dispendiosas expedições de mapeamento às regiões de caça de focas e baleias do extremo sul do Atlântico, do Pacífico e da Oceania (LAMB, 2000).

Havia uma relação de amizade e confiança entre os navegadores-exploradores e os navegadores-caçadores que ultrapassava o formalismo ou apenas as proximidades pessoais. Havia uma dupla dependência nas relações entre ambos e isto se evidencia em inúmeros encontros entre capitães promovidos em pleno Estreito de Magalhães, missões de 
salvamento dos navios naufragados, pressões por novas expedições para regiões de caça e se espelhava, inclusive, em atitudes práticas durante as viagens. Os caçadores dependiam dos mapas elaborados pelos primeiros e estes dependiam da pressão dos outros para manter suas funções, viagens e prestígio dentro da Marinha Real. No caso da expedição comandada por Philip Parker King, por exemplo, ele relata que:

Um bote veio do Adeona para nos informar que dentro de um ou dois dias este navio e seus auxiliares Uxbridge e Mercury deixariam o Estreito rumo às ilhas Falkland. Tendo isto em vista, eu preparei cartas a serem enviadas à Inglaterra e o relatório de minhas atividades ao secretário do Almirantado. Os navios passaram no dia 30 e levaram minha correspondência (KING, 1839: p. 149).

Como o comandante King deixa bastante explícito, as relações entre as companhias e a Marinha Real eram bastante profundas. Enquanto os HMS Adventure e Beagle permaneciam no Estreito realizando os mapeamentos tão desejados pelos caçadores de focas e baleeiros, seus navios eram os meios de transporte dos mapas e relatórios secretos elaborados durante as longas e dispendiosas expedições.

Britânicos ou estadunidenses, os caçadores estavam muito interessados e satisfeitos com o apoio oficial de seus governos às suas atividades na região. Apesar da evidente predominância de navios da grande potência, havia também na região ao menos uma embarcação enviada pela antiga colônia, em atividade semelhante e simultânea, a fragata USS Hudson, contatada pelo comandante King no Estreito (KING, 1839, p. 461).

É interessante notar, por outro lado, distanciamentos na forma de pensar e agir dos comandantes-exploradores e dos comandantes-caçadores. Apesar da relação de dupla dependência de ambos grupos sociais, fica evidente, na descrição do comandante King, suas críticas à forma de agir e ao que entendeu como a falta de planejamento dos caçadores. Ao visitar a costa chilena, também campo de caça bastante explorado, ele afirmou:

As focas e os leões-marinhos, outrora tão abundantes aqui, estão agora reduzidos a uma ínfima parcela devido à caça intensa. Eles desapareceram, pois foram pegos indiscriminadamente, sem preocupações quanto à idade ou sexo do animal, deixando-se praticamente nenhum para a disseminação da raça, exceto aqueles que por sorte conseguiram escapar. No presente momento, estas ilhas estão sob a guarda de um tenente incumbido de impedir que estes animais sejam mortos antes de que os mais novos fujam para o mar e possam ter ao menos uma oportunidade de crescerem e se reproduzirem (KING, 1839: p. 307). 
Os navegadores exploradores britânicos do século XIX não possuíam uma preocupação conservacionista da natureza, mas a viam como fonte de riqueza. Para eles, os caçadores de foca estavam fadados à extinção, pois atacavam com desmedida gana as zonas de caça, esgotando-as em dois ou três anos, passando a regiões cada vez mais distantes e mais difíceis de serem acessadas.

Para aqueles exploradores Ilustrados, a natureza era o reflexo da grandiosidade de Deus e deveria servir aos homens, mas cabia também a estes saberem administrar racional e cientificamente a obra divina para serem merecedores desta (WORSTER, 1998). Para eles, cabia à humanidade Ilustrada trabalhar como o Bom Pastor da obra divina e pastorear os recursos naturais para melhor explorá-los. Neste contexto, eles viam com grande preocupação a atuação dos caçadores de foca e baleeiros - mesmo os britânicos ou os estadunidenses - e apesar das relações próximas e de dependência com estes (DRAYTON, 2000).

Ao público leitor de seus relatos, o comandante King entendia que deveria explicitar as dificuldades enfrentadas pelos caçadores, mas também sua péssima gestão daqueles recursos naturais. Caso a ganância fosse bem administrada, como os chilenos estavam tentando fazer, havia a possibilidade de se manter os campos de exploração abertos durante bastante tempo e a atividade econômica rentável. Em caso negativo, ele afirmava que em breve não haveria mais o que aquelas companhias caçarem.

Causava preocupação aos exploradores Ilustrados a extinção de espécies antes de serem devidamente identificadas, catalogadas e compreendidas dentro de sua possibilidade de correta exploração econômica. No caso dos caçadores de mamíferos marinhos, havia um caso bastante discutidoà época, referente ao norte do Pacífico. No Mar de Bering vivia uma espécie de peixe-boi gigante (Steller's Sea Cows - Hydrodamalis Gigas), localizada inicialmente em 1742. Caçada à exaustão devido à sua lenta velocidade, carne suculenta e quantidade de gordura, a espécie foi extinta em 1768, o que alarmou não apenas os cientistas, mas também os economistas, pois se tratava da única espécie de peixe-boi que vivia em águas geladas.

Tanto os caçadores quanto os Ilustrados se baseavam na Bíblia para legitimar seus conceitos e ação, os primeiros entendendo que cabia aos homens - imagem e semelhança de Deus - explorarem a natureza devido à sua inerente superioridade. Já os segundos, acreditavam que deveriam compreender e administrar a obra divina. Baseados nos preceitos cristãos, os naturalistas, economistas e religiosos Ilustrados questionavam, no entendimento de Donald Worster, "se não seria prudente proteger 'estes pássaros aparentemente sem valor' - ao menos até que fosse determinada qual parte lhes seria assegurada na economia da natureza" (WORSTER, 1998: p. 52). 
As preocupações racionalistas e cientificistas dos comandantes da Marinha Real são uma marca nos relatos de viagens analisados. Além de descreverem os animais caçados e criticarem a exploração irracional deste recurso natural, também procuraram - não como foco central de suas atividades, mas de forma complementar - combater lendas que se perpetuavam nas descrições anteriormente publicadas das regiões visitadas.

O caso mais emblemático deste esforço Iluminista dos comandantes-exploradores foi o do comandante Phillip Parker King ao contatar os indígenas da Patagônia. Descritos, desde o relato de Pigafetta da expedição de Magalhães, como gigantescos, estes homens foram contatados, comparados e medidos pelo racional britânico do século XIX:

\begin{abstract}
Nós ainda não havíamos estabelecido comunicações com este povo e podíamos pensar que eram mesmo gigantes, pois aparentavam ser 'muito largos' enquanto estavam no topo da colina. Esta decepção ótica ocorreu, sem dúvidas, por conta de uma miragem: havia muita neblina (...). Aproximadamente cinquenta patagões estavam reunidos (...). Eles tinham entre cinco e seis pés de altura [1,5 a 1,8 metro], apenas um excedendo esta medida, segundo as medições realizadas pelo capitão Stokes (...). (KING, 1839: pp. 85 e 96).
\end{abstract}

O comandante explicou aos seus leitores a disseminação das lendas sobre o gigantismo dos patagões, desde Pigafetta, por praticamente todos os viajantes que passaram por aquelas terras e publicaram seus relatos - demonstrando esforço para embasar seu próprio conhecimento e descrição. Na sequência recorreu, com os indígenas, a procedimentos semelhantes aos empregados juntos à fauna e flora: reuniu uma quantidade significativa de espécimes, os comparou, mediu e concluiu que eram maiores do que os ingleses, mas não gigantes - talvez semelhantes aos holandeses.

Estes povos, chamados pelos europeus de patagões e fueginos, medidos, comparados e catalogados por King, viviam nas terras visitadas pelos exploradores, observavam aquela movimentação e eventualmente entravam em contato.

\title{
As populações do Estreito e suas relações com os viajantes
}

Enquanto os europeus atravessavam o Estreito, não deixavam de se comunicar e comercializar com os indígenas que habitavam a região. Estes, passaram praticamente dois 
séculos e meio acompanhando o ritmo do comércio inter-oceânico que cruzava a região, mas a situação mudou na segunda metade do século XVIII.

Os povos nativos do sul da Patagônia e da Terra do Fogo eram parte essencial nas viagens à região, pois forneciam carne de guanaco (Lama guanicoe), peles e peixes para os veleiros e seus capitães, tementes do escorbuto, em troca de roupas, artigos metálicos e álcool.

Com a chegada dos veleiros caçadores, estes indígenas passaram a fornecer peles, mas logo os europeus notaram que, em número reduzido, com outras tecnologias e outras formas de lidar com os animais, os indígenas eram incapazes de fornecer as peles desejadas - mesmo se passassem o ano inteiro caçando. Segundo o comandante Pringle Stokes, do HMS Beagle:

Os únicos artigos que eles podem comercializar, produtos de suas parcas técnicas e armas, são as peles de focas e outros animais. Eu arrisco dizer que a pelaria que eles conseguiriam vender seria insuficiente para completar a carga de um único veleiro (KING, 1839: p. 77).

Aqueles indígenas não praticavam, não entendiam e não praticavam a caça em larga escala com os objetivos e princípios dos ocidentais. Sua forma de se relacionar com os animais, o ambiente e os outros povos era distinta e até oposta à dos caçadores que aportavam nos navios de caça (SARASOLA, 1999).

Os povos habitantes do extremo sul da Patagônia e da Terra do Fogo, distinguiam bastante entre si em costumes e idioma. Dentro de cada uma destas categorias homogeneizadoras criadas pelos estrangeiros ainda havia diversas subdivisões, inimizades e rivalidades locais e históricas (BRIONES; LANATA, 2002).

Os assim chamados patagões faziam parte do tronco Tehuelche, vivendo em grupos familiares. Caçavam à cavalo, principalmente guanacos e emas, mantinham alguma agricultura e praticavam intenso comércio entre os grupos patagões e outros que habitavam regiões mais a norte. Sua presença nas costas foi sentida desde a pioneira viagem de Magalhães e trocas comerciais foram constantemente mantidas com os navios de passagem e em busca de frutas e carnes frescas. No século XVIII alguns grupos sofreram influências católicas, em especial decorrentes da atuação do missionário Thomas Falkner, cujo relato publicado à época colaborou na disseminação das histórias deste povo (FALKNER, 2004).

As condições climáticas ainda mais inóspitas encontradas na Terra do Fogo fizeram com que a densidade demográfica nativa na região fosse baixa. Os grupos habitantes da 
região, denominados de fueginos, viviam em pequenos grupos familiares dispersos pelas baías e enseadas. Eles viviam da pesca e caça aos mamíferos marinhos, estabelecendo redes de trocas entre si e mantendo, também, relações comerciais com os navios ocidentais em trânsito.

As embarcações que atravessavam a região no início do século XIX mantinham contatos esporádicos com os indígenas e seus comandantes e marinheiros conheciam de longa data as histórias e os relatos de viajantes anteriores. Os nativos também estavam já bastante acostumados com o trato com os ocidentais, havendo alguns grupos que se afastavam e outros que se aproximavam à medida em que os navios se aproximavam. Havia também figuras que controlavam os contatos, evitando abusos, como Maria, uma patagã comentada por praticamente todo viajante do período e que coordenava o comércio na região, valendo-se de alguns conhecimentos do idioma espanhol, do cristianismo e dos costumes europeus (CANCLINI, 2006).

O comércio entre indígenas e ocidentais cresceu desde o século XVIII, mas surgiram pontos de tensão, pois os conceitos sobre troca e propriedade eram distintos nas sociedades envolvidas. Por um lado, os indígenas não concebiam os objetos e alimentos como propriedade particular e eventualmente se apossavam deles - atitude interpretada como roubo. Já os viajantes, por outro lado, muitas vezes tentavam enganar e tirar proveito nas negociações, fornecendo produtos quebrados ou de má-qualidade, o que gerava questionamentos, revoltas e, não raro, confusões, brigas e mortes.

O ponto central, para os ocidentais, era obter alimentos frescos. No caso das expedições de mapeamento e exploração, como as empreendidas pelos britânicos nas décadas de 1820 e 1830, quando as embarcações permaneciam por meses na região e o escorbuto assolava as tripulações, a abertura de relações comerciais com os indígenas era urgente. $O$ comandante King, em seu relato, foi bastante enfático ao descrever aos seus leitores esta relação de profunda dependência - a contragosto - que mantinham com os nativos:

O escorbuto surgiu e aumentou (...). Quase nenhum peixe era fisgado e a rede, apesar de frequentemente lançada, nunca capturava nada (...). $\mathrm{O}$ Sr. Tarn desembarcou e informou sobre nossa escassez, dizendo que trocaria tabaco e facas por quanta carne de guanaco conseguissem obter (...). Esta ampla mudança de dieta encheu-me de esperança de que os doentes, pelo menos os afetados pelo escorbuto, iriam se recuperar e que após outro grande abastecimento, que agora sabíamos como obter, talvez pudéssemos seguir viagem como pretendíamos de início. Todos puderam comer carne por uma semana e o restante era disponibilizado ao cirurgião, para uso dos doentes, o que não foi suficiente; a lista de doentes ainda crescia (KING, 1839, pp. 144, 149 e 152). 
Neste trecho do relato, depreende-se quanto aqueles navegadores evitavam o contato com os indígenas, tidos como foco de problemas. Havia tanto os conflitos originados de desentendimentos comerciais e de concepções materiais, quanto problemas de convivência entre os indígenas e os navegadores, em especial quanto ao convívio com as mulheres.

Outros conflitos ocorreram quando os fueginos dificultaram - não fica claro se intencionamente - os trabalhos de mapeamento e exploração em terra. Nestes momentos, chegavam a ocorrer escaramuças, ferimentos e até mortes, com os ocidentais confiantes em expressar e garantir o que entendiam como sua superioridade civilizacional:

\begin{abstract}
Estando próxima minha chegada, mostrei a eles o quanto estava descontente, (...) quando peguei meu mosquete e o mostrei: todos bateram em retirada (...). Não pude perder a oportunidade de deixar de informá-los que estávamos preparados para eles, disparando sobre suas cabeças. (...). Naturalmente petulantes e briguentos, também tem toda intenção de praticar o mal, limitados apenas pelo medo da punição (...) e se não têm o que querem, tentam roubá-lo, e qualquer punição consequente provavelmente provocará uma discussão (KING, 1839, pp. 317- 319).
\end{abstract}

Neste trecho, o comandante foi bastante claro e enfático aos seus leitores. Viagens como as empreendidas pela Marinha Real eram importantes e decorriam em riscos e na necessidade de afirmação da superioridade britânica. Era preciso, segundo ele, demonstrar a força das armas e explicitar a ordem e as formas tidas corretas para as relações comerciais. Ele defende a existência de distinções inerentes aos povos, sendo os indígenas pessoas más, petulantes e briguentas, incapazes de compreender e aceitar sua posição inferior, recorrendo à violência - à qual os britânicos deviam responder à altura e com superioridade, com seus mosquetes. Para ele e seus colegas, "Era, de qualquer forma, hora de conhecerem nossa superioridade" (FITZROY, 1839, p. 141).

Seu colega comandante do HMS Beagle, Robert FitzRoy, enfrentou ainda mais dificuldades com os fueginos. Um dos botes do navio foi furtado durante uma missão de reconhecimento de uma das baías e, mais do que os prejuízos materiais, havia a inaceitável, em sua compreensão e discurso, derrota moral. Ele ficou indignado com a situação, com o desaparecimento dos responsáveis e com sua própria incapacidade para identificá-los, localizá-los e puni-los.

Sua frustração ficou evidente em seu relato, pois entendia os fueginos e as relações destes com os britânicos a partir de seus próprios conceitos sobre propriedade e justiça. Incapaz de fazer valer o que entendia como seus direitos, sentia a própria Grã-Bretanha sendo atacada - e também viam ameaçados seus planos pessoais de ascensão na carreira. 
Em uma última e desesperada tentativa, sequestrou três jovens e crianças fueginos, de diferentes grupos, com o objetivo declarado de sensibilizar seus parentes a pressionar os ladrões. Chocado diante do que entendeu como a falta de qualquer civilidade em nativos que não se esforçaram para retomar seus descendentes, precisou abandonar a região e o bote por conta do cronograma da viagem, mas levou à Inglaterra aqueles jovens - e mais um quarto, que foi comprado - com o objetivo de entregá-los à catequese e depois reinseri-los na Terra do Fogo como disseminadores do cristianismo anglicano e de costumes ditos civilizados:

\begin{abstract}
Já havia decidido anteriormente que levaria os fueginos que estavam conosco para a Inglaterra; crendo que haveria maior proveito resultante do contato com nossos hábitos e língua, compensando a separação temporária de seu próprio país. Mas essa decisão não foi tomada na primeira vez em que os levei a bordo; naquele momento pensei em detê-los apenas enquanto estivéssemos em suas costas; descobrindo depois que estavam felizes e saudáveis, comecei a pensar nas diversas vantagens que eles e seus compatriotas teriam, assim como nós mesmos, se os levássemos para a Inglaterra, os educando o quanto fosse viável, e só então os trazendo de volta para a Terra o Fogo (FITZROY, 1839, pp. 458-459).
\end{abstract}

Do leitor do relato de FitzRoy, esperava-se a concordância e satisfação com a medida adotada. O comandante construiu sua argumentação procurando expressar os muitos benefícios da transposição temporária dos quatro indígenas à Inglaterra: eles seriam pessoalmente aprimorados, poderiam disseminar a religião e os costumes civilizados entre seus parentes e conterrâneos e, não menor, os próprios britânicos se beneficiariam de seu retorno.

O objetivo final era, com estes quatro nativos, estabelecer uma base local e confiável para navios aportarem e comercializarem, afinal eles estavam acostumados com o ambiente local e sabiam como sobreviver em uma região em que as diversas tentativas ocidentais de ocupação foram infrutíferas e desastrosas. Caso desse certo - o que não ocorreu - o estabelecimento desta base fuegino-britânica, seria uma importante vitória estratégica para o Império.

\title{
Considerações finais
}

As relações entre ocidentais e indígenas, no sul da Patagônia e na Terra do Fogo, nas primeiras décadas do século XIX, foram marcadas pelo contato, pelo comércio, mas não necessariamente pela amizade. Após alguns anos de más experiências, alguns povos se 
negaram a negociar com os forasteiros e se retiravam para regiões ermas, enquanto os veleiros chegavam, e observavam, à distância, a incompreendida matança de milhares de focas.

O Estreito de Magalhães e a Terra do Fogo eram estratégicos para os interesses britânicos nas primeiras décadas do século XIX. Eram local de passagem vital para o crescente comércio com o extremo oriente e também região privilegiada de atuação das companhias baleeiras e de caça às focas.

Para aquela região, dirigiam-se dezenas de embarcações de caça e comércio todo ano e as companhias pressionaram o governo para conseguirem novas e eficientes cartas náuticas de local de tão difícil trânsito. As relações entre os navios privados e os da Coroa não se restringiam à pressão, na metrópole, pela obtenção e divulgação dos dados cartográficos: os comandantes eram velhos conhecidos, mantinham íntimas relações, se ajudavam nos momentos de apuros, mas também no trânsito de informações.

Havia discordâncias quanto às estratégias adotadas na caça aos animais, mas muitas eram as semelhanças. Os comandantes-exploradores e os comandantes-caçadores olhavam para o Estreito de Magalhães e a Terra do Fogo com os olhos do Império Britânico, procurando identificar potencialidades econômicas e oportunidades estratégicas. Atravessaram a região, mapearam, caçaram, contataram os nativos locais e expressaram sempre, no local e em seus escritos, a certeza de sua superioridade e de sua razão.

O público leitor de seus relatos na metrópole, ávido pelas narrativas de aventuras reais de locais desconhecidos, satisfazia-se com suas histórias e com a certeza da grandeza e da vitória britânicas. Liam, disseminavam e legitimavam seu Império com os escritos destes comandantes navais que procuravam garantir os interesses britânicos e seus próprios pessoais.

\section{Bibliografia}

BELL, Duncan (ed). Victorian visions of global order. Empire and international relations in Nineteenth-Century political thought. Cambridge: Cambridge University Press, 2007.

BORM, Jam. Defining travel: on travel book, travel writing and terminology. IN: HOOPER, Glenn; YOUNGS, Tim (ed). Perspectives on travel writing. Hants/Vermont: Ashgate, 2004.

BRAUND, James. Impressions of Latin America and the Philippines from the accounts of Russian and German visitors, 1816-1826. IN: CICERCHIA, Ricardo Cicerchia; O'MEAGHER, 
Matthew (ed). Tales of land and sea: travel narratives of the Trans-Pacific South, 1700-1900. Unley: Australian Humanities Press, 2003.

BRIDGES, Roy. Exploration and travel outside Europe (1720-o1914). IN: HULME, Peter; YOUNGS, Tim (eds). The Cambridge companion to travel writing. $3^{\mathrm{a}}$ ed., Cambridge: Cambridge University Press, 2007.

BRIONES, Claudia; LANATA, José Luis (ed). Archaeological and Anthropological perspectives on the native peoples of Pampa, Patagonia, and Tierra del Fuego to the Nineteenth Century. Westport: Bergin \& Garvey, 2002.

CALDER, Alex; LAMB, Jonathan; ORR, Bridget. Voyages and Beaches. Pacific encounters, 1769-1840. Honolulu: University of Hawai'i Press, 1999.

CANCLINI, Arnoldo. Maria reina Tehuelche: amor y poder en la Patagonia - 1820 a 1843. Ushuaia: Zagier \& Urruty, 2006.

CICERCHIA, Ricardo Cicerchia; O'MEAGHER, Matthew (ed). Tales of land and sea: travel narratives of the Trans-Pacific South, 1700-1900. Unley: Australian Humanities Press, 2003.

DARWIN, John. The Empire project. the rise and the fall of the British world-system, 18301970. Cambridge: Cambridge University Press, 2011.

DRAYTON, Richard. Nature's government. science, imperial Britain and the 'improvement' of the world. Londres: Yale University Press, 2000.

FALKNER, Thomas. Descripción de la Patagonia y de las partes contiguas de la América del Sur. Con estudio preliminar de Raúl J. Mandrini. Buenos Aires: Taurus, 2004.

FITZROY, Robert. Narrative of the surveying voyages of His Majesty's Ships Adventure and Beagle, between the years 1826 and 1836. Londres: Henry Colburn, 1839.

GERBI, Antonello. O Novo Mundo: história de uma polêmica. Tradução de Bernardo Joffily. São Paulo: Cia das Letras, 1996.

GUEDES, Max Justo. Por mares dantes navegados. IN: MENEZES, Pedro da Cunha e. O Rio de Janeiro na rota dos Mares do Sul. Rio de Janeiro: Andrea Jakobsson, 2007.

GUILLON, Jacques. Dumont d'Urville. Paris: France-Empire, 1986.

HENARE, Amiria. Museums, Anthropology and Imperial exchange. Cambridge: Cambridge University Press, 2005. 
HORDERN, Marsden. King of the Australian Coast. the work of Phillip Parker King in the Mermaid and Barthust (1817-1822). Melbourne: Melbourne University Press, 2003.

JUNQUEIRA, Mary Anne. Os objetivos da circunavegação da U.S. Exploring Expedition (18381842): longitude, mapeamento náutico e instituição das coordenadas geográficas modernas. História, ciência, saúde-Manguinhos. Rio de Janeiro: Fiocruz, v. 19, n. 1, 2012.

KING, Phillip Parker. Narrative of the surveying voyages of His Majesty's Ships Adventure and Beagle, between the years 1826 and 1836. Londres: Henry Colburn, 1839.

LAMB, Jonathan; SMITH, Vanessa; THOMAS, Nicholas. (ed.) Exploration \& Exchange. A South Seas anthology (1680-1900). Chicago: University of Chicago Press, 2000.

LAMBERT, David; LESTER, Ana (Ed). Colonial lives across the British Empire. Imperial careering in the long Nineteenth Century. Cambridge: Cambridge University Press, 2006.

LANDES, David S. Prometeu desacorrentado: transformação tecnológica e desenvolvimento industrial na Europa ocidental, de 1750 até os nossos dias. $2^{\text {a }}$ edição, Rio de Janeiro: Campus, 2005.

MARTIN, Jose Maria Moreno; PUIG-SAMPER, Miguel Angel; REVERTE, Javier; VALLESPIN, Fernando. The Malaspina expedition: a scientific and political voyage around the world, 1789-1794. Nashville: Turner, 2010.

PHILBRICK, Nathaniel. No coração do mar. São Paulo: Cia. das Letras, 2001.

PIGAFETTA, Antonio. A primeira viagem ao redor do mundo. Porto Alegre: LP\&M, 2005.

PRATT, Mary Louise. Os olhos do Império: relatos de viagem e transculturação. Tradução de Jézio Hernani Bonfim Gutierre. Bauru: Edusc, 1999.

RUBIÉS, Joan Pau. Travel writing and ethnography. IN: HULME, Peter; YOUNGS, Tim (eds). The Cambridge companion to travel writing. $3^{\text {a }}$ edição. Cambridge: Cambridge University Press, 2007.

SALVATORE, Ricardo D. Los lugares del saber. Contextos locales y redes transnacionales en la formación del conocimiento moderno. Buenos Aires: Beatriz Viterbo Editora, 2007.

SARASOLA, Carlos Martinez. Nuestros paisanos, los indios. Vida, historia y destino de las comunidades indígenas en la Argentina. Buenos Aires: Emecé, 1999.

WASHBROOK, D. A. India, 1818-1860: two faces of colonialism. IN: PORTER, Andrew (ed). The nineteenth century. Oxford: Oxford University Press, 1999. 


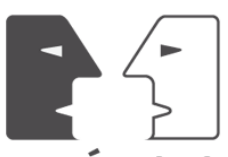

ANTÍTESES

WEDELL, James. A Voyage towards the South Pole, performed in the years 1822-1824, containing an examination of the Antartic Sea, and a visit to Tierra del Fuego. Cambridge: Cambridge University Press, 2011.

Texto recebido em 18 de março de 2014 e aprovado em 28 de abril de 2014 